\title{
RIESGO DE CONTRAER ENFERMEDADES PARASITARIAS EN LOS PARQUES PÚBLICOSDE LIMA Y CALLAO
}

\author{
Amanda Chávez V. ${ }^{1,2}$, Eva Casas A. ${ }^{1}$, Marcos Serrano M. ${ }^{1}$, Junett Cajas U. ${ }^{3}$, José \\ Velarde O. ${ }^{3}$, Virgilio La Rosa V. ${ }^{3}$ y Juan López T. ${ }^{3}$
}

\section{ABSTRACT}

The objective of this paper was to determine the contamination with Toxocara sp. in public parks of Metropolitan Lima and Callao. Turf samples were collected from 558 out of the 1,964 parks existing in Lima and Callao $(108,98,151$ and 123 from the northern, southern, eastern and western part of Lima and 78 from Callao) during December 1998 and August 199 using the double "W" method. Samples were processed by the flotation method using CINa saturated solution. A sample was considered positive when presented at least one egg of Toxocara sp. The eggs were incubated and orally inoculated to mice and quails to verify the viability of eggs. Parks were grouped according to the level of conservation as good (well covered with grass), moderate (around 50\% covered with grass) and poor conserved (without grass); and according to the social economic level as high, middle-high, middle, middle-low and low. The prevalence rate was $34 \pm 9 \%$ (mean \pm confidence interval), $30 \pm 9,41 \pm 8,63 \pm 9$ and $37 \pm 11 \%$ for parks in northern, southern, eastern and western part of Lima and Callao, respectively. Contamination level was 73, 49 and $16 \%$ in parks with good, moderate and poor level of conservation, whereas according to the social economic level was $73,62,47,29$ and $30 \%$ in parks with high, middle-high, middle, middle-low and low social economic levels, respectively. Abundant green material and high humidity in good conserved parks would favour conservation of Toxocara sp. eggs. On the other hand, the absence of Toxocara sp. eggs in poorly conserved parks would be due to direct solar radiation on the eggs. Finally, inoculated mice and quails developed migrant larva, which is indicative of the infective capacity of the eggs.

Key words: Toxocara, parks, ascarides, migrant larva, zoonosis

\section{RESUMEN}

El objetivo del trabajo fue determinar la contaminación con huevos de Toxocara sp. de los parques públicos de Lima Metropolitana y Callao. Muestras de tierra y césped de 558 de los 1964 parques existentes en los distritos ubicados en Lima Metropolitana y el Callao ( 108 del cono norte, $98 \mathrm{del}$ cono sur, 151 del cono este, 123 del cono oeste y 78 del Callao) fueron colectadas durante los meses de diciembre de 1998 hasta agosto de 1999, empleando el método de doble "W" y procesadas mediante el método de flotación con solución sobresaturada de ClNa. Los huevos recolectados fueron incubados e inoculadas vía oral a ratones y codornices para verificar la viabilidad a los huevos. Los parques fueron categorizados según su estado de conservación en parques bien conser-

\footnotetext{
' Laboratorio de Microbiología y Parasitología, FMV-UNMSM

${ }^{2}$ E-mail: a_chavez_g@hotmail.com

${ }^{3}$ Práctica privada
} 
vados (césped en toda su área), medianamente conservados (césped en cerca del $50 \%$ del área) y mal conservados (sin césped); y según el estrato socioeconómico de la población circundante en estratos de poder adquisitivo alto, medio alto, medio, mediobajo y bajo. Se encontró una prevalencia de $34 \pm 9 \%$ (promedio \pm intervalo de confianza), $30 \pm 9 \%, 41 \pm 8 \%, 63 \pm 9 \%$ y $37 \pm 11 \%$, para los distritos de los conos norte, sur, este, oeste y el Callao, respectivamente. El porcentaje de parques contaminados según el estado de conservación fue de 73,49 y $16 \%$ para parques bien, medianamente y mal conservados, respectivamente, en tanto que según el nivel socioeconómico fue de 73, 62, 47, 29 y $30 \%$ para parques de nivel económico alto, medio alto, medio, medio-bajo y bajo, respectivamente. La vegetación y humedad existente en los parques bien conservados favorece la sobrevivencia de los huevos de Toxocara sp, en tanto que su escaso número en los parques mal conservados se debería a su destrucción por los rayos solares. Por último, los huevos larvados que fueron inoculados en ratones y codornices desarrollaron larvas migrantes viscerales indicando su alto grado de patogenicidad. Se concluye que los parques mejor conservados tienden a presentar una mayor presencia de huevos de Toxocara sp, por lo que se deberían realizar campañas de educación sanitaria, desparasitaciones periódicas de las mascotas, reglamentar la circulación de perros en los parques públicos, e incentivar el uso de bolsas plásticas para recolectar las deyecciones de los perros que visiten los parques o implementar letrinas públicas para mascotas.

Palabras clave: Toxocara, parques, ascáridos, larva migrante, zoonosis

\section{INTRODUCCIÓN}

La toxocariosis constituye una zoonosis parasitaria producida por la ingestión de huevos infectivos de Toxocara sp., parásito que frecuentemente se encuentra en el intestino delgado del perro y el gato. La contaminación de los parques públicos con huevos infectivos de Toxocara sp. constituye un problema en salud pública, ya que la ingestión de estos huevos infectivos por el hombre (especialmente niños) ocasiona enfermedades conocidas como Síndrome de la Larva Migrante Visceral (LMV) y Síndrome de la Larva Migrante Ocular (LMO) (Schanstz y Glickman, 1981). Los signos clínicos incluyen tos e infiltración pulmonar signos evidentes en un tercio de los pacientes. El asma y la bronquitis recurrente están asociadas a los anticuerpos contra Toxocara sp. (LópezVelez et al., 1996).

Estudios sobre contaminación de parques realizados en otros países muestran grandes diferencias; así en Cuba y Brasil se hallaron prevalencias de 42 y $56 \%$, respectivamente, mientras que en Osaka, Japón se encontró el 75\% (Duménico y Gálvez, 1995;
Santarem et al., 1998; Abe y Yasukawa, 1997). Los primeros estudios acerca de la contaminación de parques públicos en Lima Metropolitana con huevos de Toxocara sp. fueron realizados por Guerrero (1975) quien halló una prevalencia de $24 \%$, en tanto que Buitrón (1976) reportó el 56\% de parques contaminados en el área urbana de Paramonga.

El objetivo del presente trabajo fue evaluar la contaminación con huevos de Toxocara sp. de los parques públicos de Lima Metropolitana y el Callao.

\section{Materiales Y Métodos}

\section{Localidades}

El estudio fue realizado en 5 etapas en todos los distritos de Lima Metropolitana y el Callao. El Cono Norte estuvo representado por los distritos de Ancón, Carabayllo, Comas, Independencia, Los Olivos, Puente Piedra, Rímac, San Martín de Porres y Santa Rosa (La Rosa, 2000); el Cono Sur por los distritos de Villa El Salvador, Villa María del Triunfo, San Juan de Miraflores, y Chorrillos 
(Cajas, 1999); el Cono Este por Ate-Vitarte, Chaclacayo, Cieneguilla, El Agustino, La Molina, San Juan de Lurigancho y Santa Anita (Serrano, 2000); el Cono Oeste por Breña, Jesús María, La Victoria, Lima, Lince, Magdalena del Mar, Miraflores, PuebloLibre, San Borja, San Isidro, San Luis, y San Mrguel (López, en prensa); y la Provincia Constitucional del Callao por los distritos de Bellavista, Callao, Carmen de la Legua, La Perla, La Punta y Ventanilla (Velarde, 1999).

El estudio en los parques de Lima Metropolitana se efectuó durante los meses de enero a agosto de 1999, mientras que en los distritos del Callao se realizó en diciembre de 1998. La temperatura y humedad ambiental varió de 16 a $26.3{ }^{\circ} \mathrm{C}$ y de 79 a $94 \%$, respectivamente (Von Humbolt, $1999^{4}$, Marina de Guerra del Perú, 1998 ${ }^{5}$, SENAMHI, $1999^{6}$ ).

\section{Metodología}

Se obtuvo entre 3 a $5 \mathrm{~kg}$ de tierra y césped de cada uno de los parques mediante la técnica de la doble W. Las muestras fueron procesadas por el método de flotación con solución sobresaturada de $\mathrm{NaCl}$, considerándose positiva aquella muestra que presentara al menos un huevo de Toxocara sp.

Los parques fueron clasificados de acuerdo al estado de conservación y al estrato socioeconómico del distrito. La clasificación de los parques según el estado de conservación fue: bien conservados (césped en toda su área), medianamente conservados (césped en cerca del $50 \%$ del área) y mal conservados o baldíos (sin césped). Los lineamientos para la clasificación por estrato socioeconómico se hicieron en base a las directivas del Instituto Nacional de Estadística e Informática (INEI, 1998), siendo éstos los estratos socioeconómicos alto, medio-alto, medio, medio-bajo, y bajo.

Se verificó la viabilidad de los huevos de Toxacara sp. obtenidos en el análisis de flotación. Los huevos fueron incubados en una solución de bicromato de potasio al $2.5 \%$ por 15 a 30 días con el fin de obtener huevos larvados (formas infectivas). Los huevos (n $=1,500$ ) fueron inoculados vía oral en ratones y codornices, los que fueron desparasitados 7 días antes de la inoculación. Éstos se sacrificaron al cabo de $1,5,10,15$ y 20 días postinoculación para determinar lesiones macroscópicas e histopatológicas en órganos. Asimismo, muestras de tejidos fueron procesadas mediante la técnica de Baerman para la obtención de larvas migrantes.

\section{Diseño Estadístico}

El tamaño de la población muestral se determinó con la fórmula de proporciones en poblaciones finitas (Daniel, 1996), siendo de $108,98,151,123$ y 78 parques para los distritos de los conos norte, sur, este y oeste de Lima Metropolitana y del Callao. El número de parques por distrito se determinó en forma proporcional al número total de parques de la zona en estudio. Los resultados obtenidos fueron expresados en forma porcentual, calculándose sus respectivos intervalos de confianza, a través de la aproximación normal a la binomial. La selección de los parques fue al azar.

\section{Resultados Y Discusión}

El porcentaje de parques contaminados con huevos de Toxocara sp. fue de 34.3

\footnotetext{
${ }^{4}$ Información proporcionada por la Estación Metereológica de la Universidad Agraria-La Molina

${ }^{5}$ Información proporcionada por la Dirección de Hidrografía y Navegación de la Marina de Guerra del Perú, Chucuito-Callao

${ }^{6}$ Información correspondiente al periodo diciembre 1998 - agosto 1999, proporcionada por el Servicio Nacional de Meteorología e Hidrología (SENAMHI)
} 
$\pm 9.0 \%$ en los distritos del cono norte, $29.6 \pm$ $9 \%$ en el cono sur, $41.1 \pm 7.8 \%$ en el cono este, $63.4 \pm 9 \%$ en el cono oeste, y $37.0 \pm$ $11 \%$ en el Callao. Las prevalencias encontradas en este estudio (Cuadros 1, 2, 3, 4 y 5) son superiores al $24 \%$ que fuera reportado por Guerrero (1975) en un estudio previo.

El mayor porcentaje de parques positivos a Toxocara sp se presentó en aquellos que tenían estados de conservación coincidentes con los niveles de bien y a mediana mente conservados, en tanto que los parques mal conservados o baldíos presentaron las tasas de contaminación más bajas (Cuadro 6).

En relación con el estrato socioeconómico, se encontró que los parques correspondientes a los niveles alto y medio-alto tuvieron los mayores porcentajes de contaminación con huevos de Toxocara sp. Los parques ubicados en estratos económicos medio-bajo y bajo tuvieron los menores porcentajes de contaminación (Cuadro 7).

Cuadro 1. Porcentaje de parques positivos a huevos de Toxocara sp. en los distritos del Cono Norte de Lima Metropolitana

\begin{tabular}{|c|c|c|c|}
\hline Distritos & $\begin{array}{l}N^{\circ} \text { de Parques } \\
\text { Muestreados }\end{array}$ & $\begin{array}{l}\mathrm{N}^{\circ} \text { de Parques } \\
\text { Contaminados }\end{array}$ & $\begin{array}{c}\text { Parques Positivos } \\
(\%) \pm \text { I.C. }\end{array}$ \\
\hline Ancón & 4 & 1 & 25.0 \\
\hline Carabayllo & 6 & 1 & 16.7 \\
\hline Comas & 24 & 9 & 37.5 \\
\hline Independencia & 11 & 3 & 27.3 \\
\hline Los Olivos & 25 & 11 & 44.0 \\
\hline Puente Piedra & 4 & 1 & 25.0 \\
\hline Rímac & 9 & 3 & 33.3 \\
\hline San Martín de Porres & 24 & 8 & 33.3 \\
\hline Santa Rosa & 1 & 0 & 0 \\
\hline Total & 108 & 37 & $34.3 \pm 9.0 \%$ \\
\hline
\end{tabular}

Cuadro 2. Porcentaje de parques positivos a huevos de Toxocara sp. en los distritos del Cono Oeste de Lima Metropolitana

\begin{tabular}{|c|c|c|c|}
\hline Distritos & $\begin{array}{l}\mathrm{N}^{\circ} \text { de Parques } \\
\text { Muestreados }\end{array}$ & $\begin{array}{l}\mathrm{N}^{\circ} \text { de Parques } \\
\text { Contaminados }\end{array}$ & $\begin{array}{l}\text { Parques Positivos } \\
\text { (\%) } \pm \text { I.C. }\end{array}$ \\
\hline Breña & 4 & 4 & 100.0 \\
\hline Jesús María & 4 & 2 & 50.0 \\
\hline La Victoria & 12 & 7 & 58.3 \\
\hline Lima & 20 & 10 & 50.0 \\
\hline Lince & 2 & 1 & 50.0 \\
\hline Magdalena del Mar & 2 & 1 & 50.0 \\
\hline Miraflores & 13 & 8 & 61.5 \\
\hline Pueblo Libre & 11 & 8 & 72.7 \\
\hline San Borja & 11 & 9 & 81.8 \\
\hline San Isidro & 11 & 9 & 81.8 \\
\hline San Luis & 5 & 4 & 80.0 \\
\hline San Miguel & 20 & 13 & 65.0 \\
\hline Surquillo & 8 & 2 & 25.0 \\
\hline Total & 123 & 78 & $63.4 \pm 9.0$ \\
\hline
\end{tabular}


Cuadro 3. Porcentaje de parques positivos a huevos de Toxocara sp. en los distritos del Cono Sur de Lima Metropolitana

\begin{tabular}{|c|c|c|c|}
\hline Distritos & $\begin{array}{l}\mathrm{N}^{\circ} \text { de Parques } \\
\text { Muestreados }\end{array}$ & $\begin{array}{l}\mathrm{N}^{\circ} \text { de Parques } \\
\text { Contaminados }\end{array}$ & $\begin{array}{l}\text { Parques Positivos } \\
(\%) \pm \text { I.C. }\end{array}$ \\
\hline Villa el Salvador & 26 & 7 & 26.9 \\
\hline Villa María del Triunfo & 32 & 8 & 25.0 \\
\hline San Juan de Miraflores & 26 & 8 & 30.8 \\
\hline Chorrillos & 14 & 6 & 42.9 \\
\hline Total & 98 & 29 & $29.6 \% \pm 9.0$ \\
\hline
\end{tabular}

Cuadro 4. Porcentaje de parques positivos a huevos de Toxocara sp en los distritos del Cono Este de Lima Metropolitana

\begin{tabular}{|c|c|c|c|}
\hline Distritos & $\begin{array}{l}N^{\circ} \text { de Parques } \\
\text { Muestreados }\end{array}$ & $\begin{array}{l}\mathrm{N}^{\circ} \text { de Parques } \\
\text { Contaminados }\end{array}$ & $\begin{array}{l}\text { Parques Positivos } \\
(\%) \pm \text { I.C. }\end{array}$ \\
\hline Ate-Vitarte & 38 & 14 & 36.8 \\
\hline Chachacayo & 10 & 2 & 20.0 \\
\hline Cieneguilla & 7 & 1 & 14.3 \\
\hline El Agustino & 13 & 5 & 38.5 \\
\hline La Molina & 34 & 19 & 55.9 \\
\hline San Juan de Lurigancho & 33 & 15 & 45.5 \\
\hline Santa Anita & 16 & 6 & 37.5 \\
\hline Total & 151 & 62 & $41.1 \% \pm 7.8$ \\
\hline
\end{tabular}

Cuadro 5. Porcentaje de parques positivos a huevos de Toxocara sp en los distritos del Callao

\begin{tabular}{|c|c|c|c|}
\hline Distritos del Callao & $\begin{array}{l}\mathrm{N}^{\circ} \text { de Parques } \\
\text { Muestreados }\end{array}$ & $\begin{array}{l}\mathrm{N}^{\circ} \text { de Parques } \\
\text { Contaminados }\end{array}$ & $\begin{array}{l}\text { Parques Positivos } \\
\qquad \%) \pm \text { I.C. }\end{array}$ \\
\hline Bellavista & 21 & 10 & 47.6 \\
\hline Callao & 29 & 10 & 34.5 \\
\hline Carmen de la Legua & 3 & 1 & 33.3 \\
\hline La Perla & 15 & 2 & 13.3 \\
\hline La Punta & 3 & 3 & 100.0 \\
\hline Ventanilla & 7 & 3 & 42.9 \\
\hline Total & 78 & 29 & $37.2 \% \pm 11.0$ \\
\hline
\end{tabular}


Cuadro 6. Número de parques evaluados de Lima Metropolitana y el Callao y porcentaje de parques positivos a huevos de Toxocara sp. según su estado de conservación

\begin{tabular}{lcccccc}
\hline \multirow{2}{*}{$\begin{array}{l}\text { Ubicación } \\
\text { Geográfica }\end{array}$} & \multicolumn{2}{c}{ Bien conservado } & \multicolumn{2}{c}{ Medianamente conservado } & \multicolumn{2}{c}{ Mal conservado } \\
\cline { 2 - 7 } & $\mathrm{N}^{\circ}$ & $\%$ & $\mathrm{~N}$ & $\%$ & $\mathrm{~N}^{\circ}$ & $\%$ \\
\hline Cono Norte & 31 & 64.5 & 29 & 27.6 & 48 & 18.8 \\
Cono Sur & 19 & 42.0 & 17 & 47.0 & 62 & 21.0 \\
Cono Este & 39 & 92.3 & 47 & 44.7 & 65 & 7.7 \\
Cono Oeste & 77 & 71.0 & $2-6$ & 50.0 & 20 & 50.0 \\
Callao & 11 & 100.0 & 15 & 100.0 & 52 & 5.7 \\
\hline \multicolumn{1}{r}{ Total } & 177 & 73.4 & 134 & 48.5 & 247 & 16.2 \\
\hline
\end{tabular}

Cuadro 7. Porcentaje de parques de Lima Metropolitana y el Callao que fueran positivos a huevos de Toxocara sp. de acuerdo a los niveles socioeconómicos ${ }^{1}$

\begin{tabular}{|c|c|c|c|c|c|c|c|c|c|c|}
\hline \multirow{2}{*}{$\begin{array}{l}\text { Ubicación } \\
\text { Geográfica }\end{array}$} & \multicolumn{2}{|c|}{ Alto } & \multicolumn{2}{|c|}{ Medio Alto } & \multicolumn{2}{|c|}{ Medio } & \multicolumn{2}{|c|}{ Medio Bajo } & \multicolumn{2}{|c|}{ Bajo } \\
\hline & $\mathrm{N}^{\circ}$ & $\%$ & $\mathbf{N}^{\circ}$ & $\%$ & $\mathbf{N}^{\circ}$ & $\%$ & $\mathrm{~N}^{\circ}$ & $\%$ & $\mathrm{~N}^{\circ}$ & $\%$ \\
\hline Cono Norte & 2 & 50.0 & 18 & 66.7 & 29 & 37.9 & 31 & 25.8 & 28 & 17.9 \\
\hline Cono Sur & $* *$ & $* *$ & $* *$ & $* *$ & 15 & 60.0 & 23 & 17.4 & 60 & 26.7 \\
\hline Cono Este & 8 & 87.5 & 26 & 46.2 & 6 & 50.0 & 49 & 34.7 & 62 & 37.1 \\
\hline Cono Oeste & 39 & 69.2 & 60 & 66.7 & 14 & 50.0 & 7 & 42.9 & 3 & 33.3 \\
\hline Callao & 3 & 100.0 & $* *$ & $* *$ & 21 & 47.6 & 44 & 27.3 & 10 & 40.0 \\
\hline Total & 52 & 73.1 & 104 & 61.5 & 85 & 47.1 & 154 & 28.6 & 163 & 30.1 \\
\hline
\end{tabular}

En los niveles alto y medio-alto se obtuvieron los mayores porcentajes de parques positivos, debido a que los parques de esos distritos se encuentran mayoritariamente con áreas verdes debidamente establecidas (niveles bien o medianamente conservados de este estudio). Estas áreas constituyen para los dueños de mascotas los lugares predilectos para llevar a los perros a ejercitar y realizar sus deposiciones. Aquellos animales que se encuentren parasitados causarán la con- taminación del parque, que aunado a las condiciones favorables del suelo (humedad, sombra, etc), contribuirán a la sobrevivencia de los huevos infectivos por un largo tiempo.

En el estrato socioeconómico bajo, a pesar que el terreno de estos parques no es el adecuado para el desarrollo del parásito, se pudo encontrar huevos de Toxocara sp., lo que estaría indicando la presencia de otros factores, tales como el alto nivel de parasitis- 
mo, alta población canina y otros factores coincidentes como la escasez de recursos económicos. Estos factores estarían limitando la posibilidad de realizar controles antiparasitarios a las mascotas.

Se pudo aislar larvas migrantes en hígado, pulmón y musculatura de los ratones y codornices inoculadas experimentalmente, por lo que se pudo deducir que los huevos de Toxocara sp. aislados de las áreas en estudio se encontraban viables e infectivos.

\section{Recomendaciones}

- Alertar a las autoridades sanitarias y municipales sobre el peligro inminente que representa esta zoonosis.

- Educación sanitaria de la comunidad y en especial a la población en edad escolar, recomendando realizar desparasitaciones periódicas de sus mascotas y el mantenimiento de las reglas básicas de higiene.

- Reglamentar la circulación de perros en los parques públicos; sancionando a los propietarios de canes que utilicen los parques públicos como letrinas para deposición de sus perros.

- Utilizar bolsas plásticas para eliminar las deyecciones de los perros que visiten los parques, o implementar letrinas públicas para mascotas.

- Control de animales vagabundos.

\section{Literatura Citada}

1. Abe, N., A. Yasukawa. 1997. Prevalence of Toxocara spp. egg in sandpits of parks in Osaka city, Japan, with notes on the prevention of egg contamination by fence construction. J. Vet. Med. Sci. 59: 79-80.

2. Buitrón, LAA. 1976. Estudio de la contaminación de áreas de uso público con huevos de Toxocara spp en el área urbana de Paramonga - distrito de Pativilca - provincia de Chancay - departamento de Lima. Tesis bachiller, FMV - UNMSM. $25 \mathrm{p}$.

3. Cajas, J.C. 1999. Contaminación de los parques públicos con huevos de Toxocara spp. en los distritos del Cono Sur (Chorrillos, San Juan de Miraflores, Villa María del Triunfo y Villa El Salvador). Tesis Médico Veterinario, FMVUNMSM. 67 p.

4. Daniel, W. 1996. Bioestadística. Base para el análisis de las ciencias de la salud. Noriega Editores. México. 206 p.

5. Dumenico, B.; D. Gálvez. 1995. Soil contamination in Habana City with Toxocara canis eggs. Rev. Cubana Med. Trop. 47: 178-180.

6. Guerrero, M.O. 1975. Estudio de la contaminación de parques públicos de Lima Metropolitana con huevos de Toxocara spp. Tesis Médico Veterinario, FMVUNMSM. 12 p.

7. Instituto Nacional de Estadística e Informática (INEI). 1998. Planos estratificados de Lima Metropolitana a nivel de manzana, según estrato socioeconómico de los hogares. INEI. Mosaic Marking. $150 \mathrm{p}$.

8. La Rosa, V.V. 2000. Estudio de la contaminación de los parques públicos con huevos de Toxocara spp. en los distritos del cono norte (Comas, Carabayllo, Ancón, Independencia, Los Olivos, Puente Piedra, Rimac, San Martín de Porres). Tesis Médico Veterinario, FMV- UNMSM. 73 p.

9. López-Velez, R.; M.C. Turrientes; $Q$. Malo; M.S. Fenoy. 1996. 2 cases of toxocariasis. Enferm. Infecc. Microbiol. Clin. 14:.548-550.

10. Schanstz, P.M.; L.T. Glickman. 1981. Epidemiology and pathogesis of zoonotic toxocariasis. Epidemiol. Rev. 3:230-250.

11. Santarem, V.A.; I.F. Sartor; F.M. Bergamo. 1998. Contaminación by Toxocara sp. eggs in public parks and squeres in Botucatu, Sao Paulo, Brasil. Rev. Soc. Bras. Med. Trop. 31: 529-532.

12. Serrano, M.M 2000. Estudio de la contaminación de los parques públicos con 
huevos de Toxocara spp. en los distritos del cono este (Ate-Vitarte, Chaclacayo, Cieneguilla, El Agustino, La Molina, San Juan de Lurigancho, Santa Anita). Tesis Médico Veterinario, FMV- UNMSM. 73 p.
13. Velarde, J.A. 1999. Contaminación de los parques públicos de la Provincia Constitucional del Callao con huevos de Toxocara spp. Tesis Médico Veterinario, FMV- UNMSM. 50 p. 